\title{
Efficacy of Large Optic Intraocular Lenses in Myopic Eyes with Posterior Segment Pathology
}

\author{
Andreas F. Borkenstein (D) · Eva-Maria Borkenstein
}

Received: October 28, 2021 / Accepted: November 16, 2021 / Published online: November 27, 2021

(c) The Author(s) 2021

\begin{abstract}
We report a case series of patients with high myopia (axial length 25.04-27.59 mm) diagnosed with cataract and maculopathy who underwent a combined procedure of phacoemulsification with implantation of a large optic intraocular lens (IOL) and intravitreal injection. Six patients with a mean $( \pm$ standard deviation) age of $73.20 \pm 7.19$ years received the 7.0-mm optic ASPIRA-aXA IOL (HumanOptics AG, Erlangen, Germany) and intravitreal injection of aflibercept at the end of the surgery. The corrected distance visual acuity (CDVA) improved significantly $(p=0.001)$ from a preoperative $\log$ MAR of $0.87 \pm 0.28 \log$ MAR to $0.49 \pm 0.18 \log$ MAR at 10 weeks postoperatively. Even though all patients had a persisting central scotoma due to their maculopathy, there was a significant improvement in their subjective quality of life and self-autonomy. Patients reported no postoperative dysphotopsia. During surgery and postoperative examinations, the wide IOL optic permitted an enhanced view of the fundus. The IOLs remained stable after implantation, especially during the intravitreal injection at the end of
\end{abstract}

A. F. Borkenstein $(\varangle) \cdot$ E.-M. Borkenstein Borkenstein \& Borkenstein, Private Practice at Privatklinik der Kreuzschwestern Graz, Kreuzgasse 35, 8010 Graz, Austria e-mail: crustalith@gmx.at the surgery. No IOL displacement or shift of the lens was observed. Retinal diseases are sightthreatening and diminish the patient's quality of life due to reduced visual acuity and visual field defects. When cataract surgery is performed in this patient group, a reduced prognosis can be assumed. Our results show that implantation of the large optic IOL enables a wide view of the fundus during and after surgery without any additional risks or negative effects. It may also reduce the risk of dysphotopsia in cases of IOL decentration in large capsular bags, but comparative studies with a higher number of cases are needed to confirm this. A large rhexis and large IOL optic seem to be advantageous for the retinal surgeon in follow-up surgeries on the posterior segment of the eye.

Keywords: Cataract surgery; Large optic IOL; Posterior segment pathology 


\section{Key Summary Points}

Achieving a panoramic view in cataract surgery involves thinking one step ahead to enhance intraocular lens (IOL) stability in myopic eyes with posterior segment pathologies.

Implantation of a large (XL) optic IOL may reduce the risk of dysphotopsia, and it also enables a wide view of the fundus during and after surgery without any additional risks to or negative effects on the patient.

In this case series we attempt to show that adverse effects, such as dysphotopsia, may be prevented with IOL decentration in myopic eyes with large capsular bags. Further multicentric, comparative studies with higher number of cases should prove this concept.

\section{INTRODUCTION}

Cataract and age-related macular degeneration (AMD) remains among the leading causes of visual impairment globally [1]. While cataract can be treated with a simple surgical procedure, $\mathrm{AMD}$, diabetic retinopathy, and other retinal diseases are more complex to handle and require lifelong follow-ups accompanied by various therapies. These retinopathies increasingly benefit from treatment with intravitreal anti-vascular endothelial growth factor (VEGF) injections that are, in general, considered to be safe [2]. Occasionally, VEGF injection may be accompanied by severe complications, such as increased intraocular pressure (IOP), which is a major risk for the retinal nerve fiber layer [3], but it also might affect the anterior chamber in some cases [2]. The potential for complications arising from the treatment and the progression of the disease itself require regular appointments for general ocular examination and fundus imaging. In the 1990s the Beaver Dam Eye Study indicated a statistically significant relation between cataract surgery at baseline and the incidence and progression of disciform AMD. For a long time cataract surgery for retinal diseases was thought not to be beneficial; however, there is an increasing body of evidence supporting the considerable benefits of cataract surgery for the majority of patients [4]. Indeed, cataract surgery in AMD patients generally results in increased visual acuity (VA) without any increased risk of worsening the AMD [5] and an enhanced quality of life [6]. Removing the gray cloudy lens and replacing it with an IOL reduces the need for brighter lighting which itself is a benefit [7]. Whereas it is usually not difficult for the clinician to decide if a patient has cataract, it can be challenging to decide whether or not to offer surgery to the patient in question. The Danish authors of a systematic review article [7] concluded that patients with ocular comorbidity have worse visual outcomes than those without ocular comorbidities because of the lower potential for visual function, but that even patients with fundus pathology may have a favorable visual outcome. The overall satisfaction after surgery and quality of vision is complex and also depends on binocular visual acuity and can not only be measured monocularly [7].

Therefore, when cataract surgery is indicated, the surgeon needs to consider the risks both for progression of early-stage AMD into late stages of AMD or further deterioration of manifestations of late AMD. Furthermore, in the presence of advanced atrophic or neovascular AMD the question arises of whether or not the patient may benefit from cataract surgery despite already experiencing central visual loss [8].

However, one cannot dismiss postoperative cataract complications, such as capsular phimosis, lens epithelial cell fibrosis, and anterior capsule contraction-all complications which may reduce vision. As the maculopathy itself and concomitant scotomas already restrict visual acuity in patients, the primary aim should be to avoid or minimize further complications. Authors of studies on other retinal pathologies have reported that a larger capsulorhexis might prevent anterior capsular contraction [9] and enhance the view of the fundus 
[10]. Capsulorhexis sizes of $\geq 6.0 \mathrm{~mm}$ have been recommended [11], although this is not feasible in most available intraocular lenses (IOLs) with an optic diameter of $6.0 \mathrm{~mm}$. A too small or non-existent rhexis-IOL overlap can increase the risk of IOL tilt, decentration, posterior and anterior capsular opacification, and other disturbances [12]. When performing cataract surgery in patients with maculopathies and other retinal diseases, "thinking one step ahead" to prevent these potential complications and side effects while considering additional diagnostic appointments and procedures should be a good approach.

Here we present a case series of patients suffering from maculopathies and cataract who received the Aspira-aXA IOL with a 7.0-mm-diameter optic (HumanOptics AG, Erlangen, Germany) (Fig. 1). Our the aim was to evaluate the above-mentioned approach in these patients. A 7.0-mm optic is more likely to be completely covered by the anterior capsulotomy and has been shown to be more stable in combination with gas compression [13]. Moreover, the large optic should enable a wider peripheral view onto the fundus, which could be beneficial for the ophthalmologist in the management of retinal diseases (Fig. 2). Many patients suffering from central visual loss rely

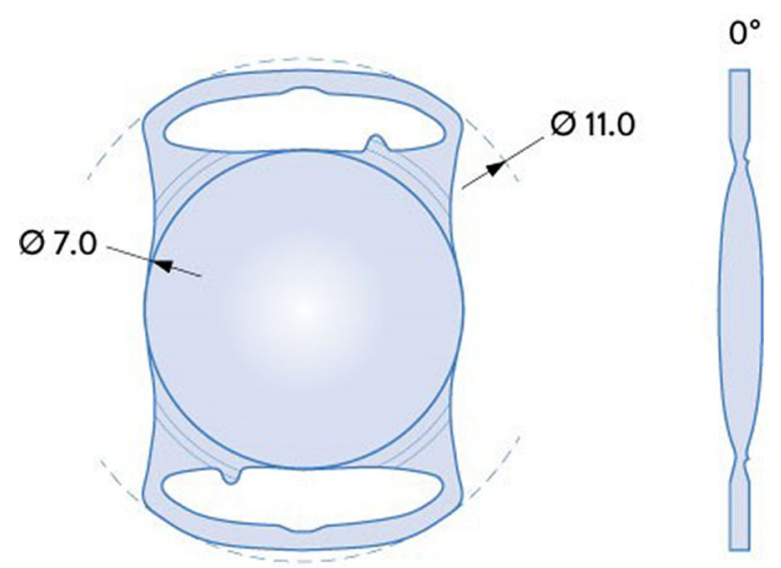

Fig. 1 Specifications of the Aspira-aXA intraocular lense with cut-out haptics and $360^{\circ}$ sharp edge (HumanOptics AG) on their peripheral vision and even adapt to using a retinal location that is not affected by their disease [14]. A "panoramic" fundus view might help the clinician to treat the disease and keep that region as healthy as possible. In the course of maculopathies, especially in diabetic retinopathy, the peripheral retina must also be monitored closely. It is important that the ophthalmologist has good insight in the disease in order to quickly detect changes. In addition, a larger rhexis and large IOL optic is advantageous for the retinal surgeon in follow-up surgeries on the posterior segment of the eye.

The current study adhered to the tenets of the Declaration of Helsinki of 1964 and its later amendments, and all patients gave their written informed consent to publish their case. In this case report only standard procedures and devices with CE-mark were used.

\section{CASE PRESENTATION}

We scheduled five patients (6 eyes) aged between 65 and 82 years (mean \pm standard deviation [SD]: $73.20 \pm 7.19)$ for cataract surgery and combined intravitreal injection. All patients were diagnosed with advanced cataract (cataracta provecta) and maculopathy due to diabetic macular edema or wet AMD. The patients were myopic or highly myopic (spherical equivalent $-5.0 \mathrm{D}$ or less or axial length $\geq 25.0 \mathrm{~mm}$ ). In each case, visual acuity was restricted by the presence of central scotoma (Table 1).

All surgeries were uneventful. The clear cornea incision size was $2.4 \mathrm{~mm}$ in all cases. Following a standard phacoemulsification procedure, each patient received the ASPIRAaXA monofocal IOL with a 7.0-mm optic. This hydrophilic acrylic lens has a special cut-out haptic design to provide high stability. While this IOL has a 7.0-mm optic, its overall diameter is $11.0 \mathrm{~mm}$; therefore, we increased capsulorhexis size to be between 1 and $6.5 \mathrm{~mm}$ larger than our standard capsulorhexis $(5.5 \mathrm{~mm})$. We used the SAFELOADER delivery system for IOL implantation as recommended by the manufacturer. At the end of the surgery, all patients received intravitreal injections of $40 \mathrm{mg} / \mathrm{ml}$ 

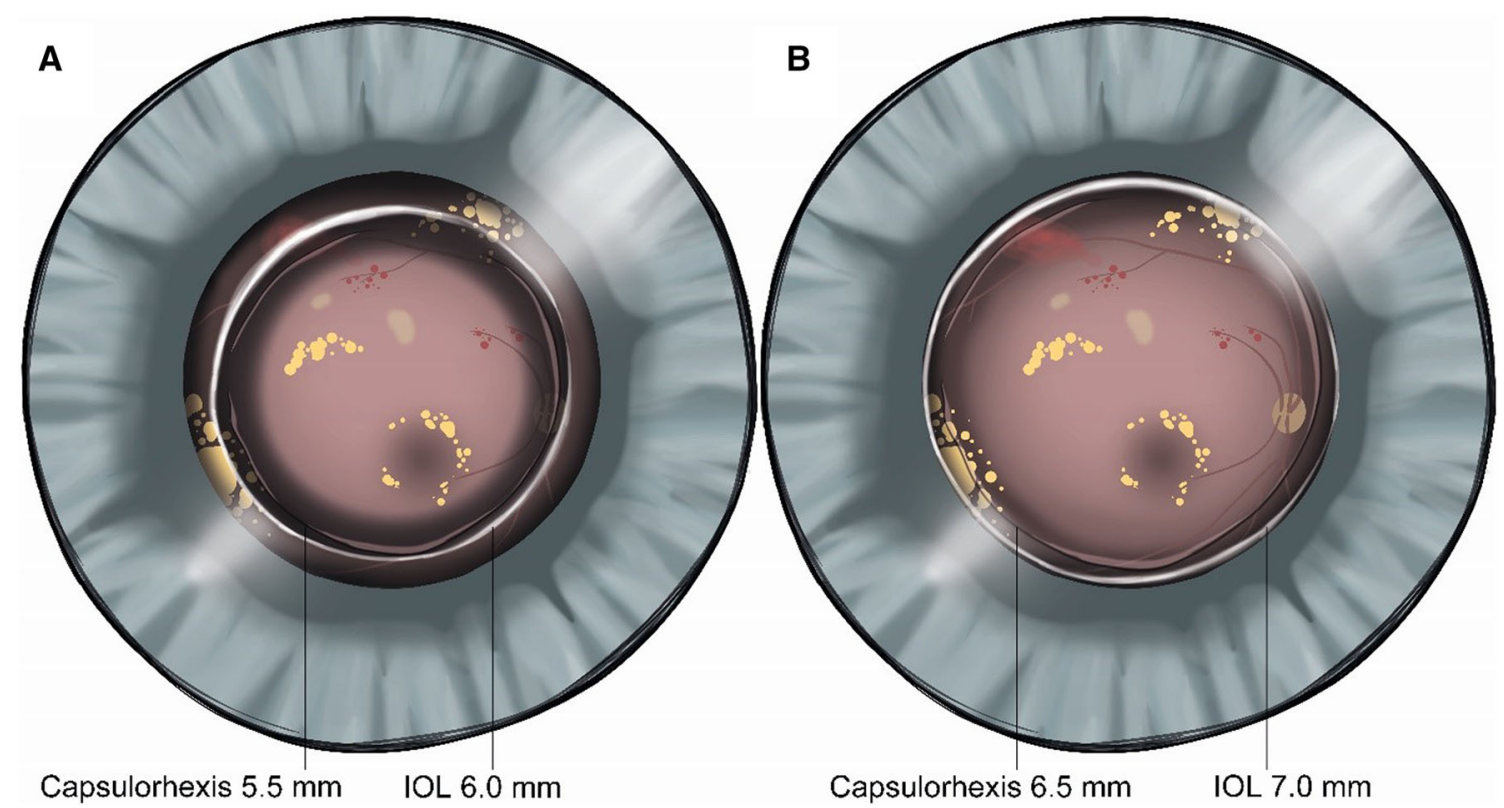

Fig. 2 Schematic drawings of a 6.0-mm intraocular lens (IOL) and 5.5-mm capsulorhexis (a) and of a 7.0-mm IOL and $6.5 \mathrm{~mm}$ rhexis $(\mathbf{b})$

aflibercept/Eylea ${ }^{\circledR}$ formulation (Bayer AG, Leverkusen, Germany) to treat their maculopathy. In this first case series, patients with maculopathy due to diabetic retinopathy as well as those with AMD were included. Additionally, intraoperative "IOL vis a tergo" was not noticed during irrigation and aspiration at the end of surgery; this can only be described from clinical observation. With standard IOLs with smaller optics and more filigree haptics, partial movements and shifts of the IOL can be observed during the injection of fluid into the vitreous body. This is just an observation of the author and cannot be scientifically proven with measurements at the present time. We did not note any effects (IOL movement or shift) during intravitreal injection in these six cases. Postoperatively, no complications were observed. Despite the remaining scotoma, VA improved significantly in all patients, with a mean $( \pm S D)$ corrected distance visual acuity (CDVA) of $0.49 \pm 0.18 \log$ MAR 10 weeks postoperatively versus a CDVA of $0.87 \pm 0.28$ logMAR preoperatively ( $p=0.001$; Table 2 ). Patients reported being very satisfied with the visual outcome, including a positive impact on their daily activities and quality of life. When asked, all patients recognized their central scotoma, but said it was less bothersome after surgery. They also reported brighter visual images than before surgery. In addition, the change in patient-reported quality of life was evaluated with a questionnaire and a point system ranging from 0 to 10 , with 10 being the highest rating (Table 3). Improvement was noted in all six cases after surgery. All patients rated the overall condition regarding life quality and self-autonomy after surgery better than before. There was a correlation of overall satisfaction to VA and size of the central scotoma. Although self-evident, it should be stated that removal of the clouded, brownish lens and implantation of a clear IOL alone leads to improvement. Moreover, the size and extent of the affected area of the macula is crucial. These are critical limitations in this small case series and should be considered in large, multicenter, comparative studies to further elucidate the potential differences or benefits of the procedure. 
Table 1 Preoperative demographic data for all cases

\begin{tabular}{|c|c|c|c|c|c|c|}
\hline $\begin{array}{l}\text { Case } \\
\text { no. }\end{array}$ & $\begin{array}{l}\text { Gender/age } \\
\text { (years) }\end{array}$ & Disease & Diagnosis & $\begin{array}{l}\text { CDVA } \\
(\log M A R)\end{array}$ & SE (D) & $\begin{array}{l}\text { Biometry (AL/ACD) } \\
(\mathrm{mm})\end{array}$ \\
\hline 1 & Female/79 & Wet AMD & $\begin{array}{l}\text { Cataracta } \\
\text { provecta } \\
\text { Macular edema }\end{array}$ & 0.70 & -4.38 & $25.11 / 3.60$ \\
\hline 2 & & Wet AMD & $\begin{array}{l}\text { Cataracta } \\
\text { provecta } \\
\text { Macular edema }\end{array}$ & 1.00 & -5.00 & $25.04 / 3.45$ \\
\hline 3 & Male/65 & $\begin{array}{l}\text { Diabetic } \\
\text { retinopathy }\end{array}$ & $\begin{array}{l}\text { Cataracta } \\
\text { provecta } \\
\text { Macular edema }\end{array}$ & 0.52 & -13.25 & $26.43 / 3.84$ \\
\hline 4 & Female/68 & Wet AMD & $\begin{array}{l}\text { Cataracta } \\
\text { provecta } \\
\text { Macular edema }\end{array}$ & 0.70 & -10.25 & $25.62 / 3.11$ \\
\hline 5 & Male/72 & $\begin{array}{l}\text { Diabetic } \\
\text { retinopathy }\end{array}$ & $\begin{array}{l}\text { Cataracta } \\
\text { provecta } \\
\text { Macular edema }\end{array}$ & 1.00 & -16.25 & $27.59 / 3.32$ \\
\hline 6 & Female/82 & Wet AMD & $\begin{array}{l}\text { Cataracta } \\
\text { provecta } \\
\text { Macular edema }\end{array}$ & 1.30 & -9.38 & $26.17 / 3.09$ \\
\hline
\end{tabular}

$A C D$ Anterior chamber depth, $A L$ axial length, $A M D$ age-related macular degeneration, $C D V A$ corrected distance visual acuity, $S E$ spherical equivalent

Table 2 Postoperative outcome for all cases

\begin{tabular}{lllr}
\hline Case no. & IOL power $(D)$ & CDVA (logMAR) & SE (D) \\
\hline 1 & 16.5 & 0.30 & -1.00 \\
2 & 17.0 & 0.70 & -0.75 \\
3 & 10.0 & 0.30 & -1.75 \\
4 & 14.5 & 0.40 & -0.75 \\
5 & 8.0 & 0.52 & -1.38 \\
6 & 13.5 & 0.70 & -1.00 \\
\hline
\end{tabular}

IOL Intraocular lens

The large IOL optic and a wider capsulorhexis enabled us have a better view during the surgery and intravitreal injection as well as a clear view of the fundus at the postoperative visits (Figs. 3, 4). This enhanced view of the fundus was of considerable value in terms of 
Table 3 Assessing change in patient-reported quality of life, evaluated with a point system, ranging from 0 to 10 , ten being the highest rating

\begin{tabular}{|r|r|r|r|}
\hline Case no & Preoperative & Postoperative & $\begin{array}{r}\text { Self- } \\
\text { reported }\end{array}$ \\
\hline 1 & 3 & 7 & BTB \\
\hline 2 & 1 & 4 & BTB \\
\hline 3 & 3 & 7 & BTB \\
\hline 4 & 2 & 4 & BTB \\
\hline 5 & 3 & 5 & BTB \\
\hline 6 & 3 & 5 & BTB \\
\hline Mean & $\mathbf{2 , 5}$ & $\mathbf{5 , 3}$ & \\
\hline
\end{tabular}

$B T B$ better than before, $n=6, S$ Same compared to before, $\mathrm{n}=0, W T B$ worse than before, $n=0$
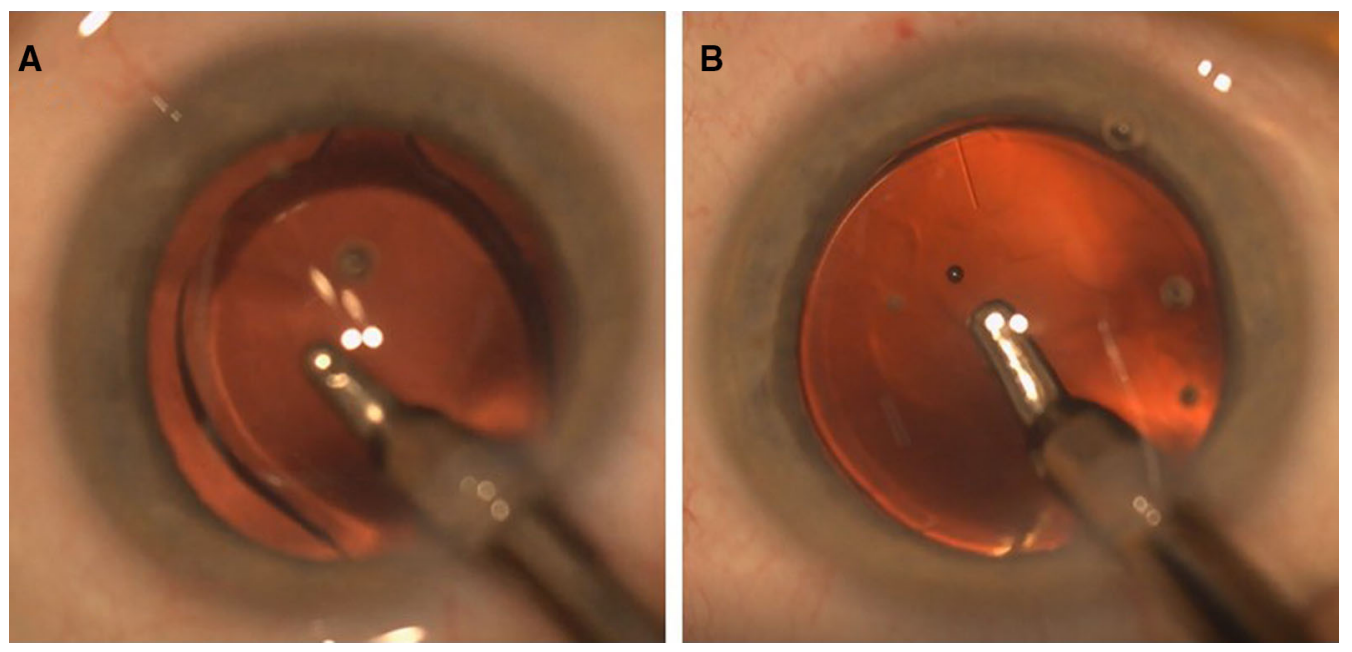

Fig. 3 Comparison of the intraoperative view with a $6.0-\mathrm{mm} \mathrm{IOL} \mathrm{(a)} \mathrm{and} \mathrm{a} \mathrm{7.0-mm} \mathrm{IOL} \mathrm{(b).} \mathrm{Note} \mathrm{the} \mathrm{shadow} \mathrm{of} \mathrm{the} \mathrm{optic}$ rim of the $6-\mathrm{mm}$ IOL

assessing progression of the retinal disease at the follow-up visits. We noted improved optical coherence tomography of the maculopathy, as the edge of the capsulorhexis did not obscure the area of interest. If capsular shrinkage, phimosis, and incipient posterior capsule opacification (PCO) in the periphery were present, they did not interfere with the view of the fundus and the macula. We found this view of the retina to be better than that with the standard-sized 6.0-mm IOLs. Lastly, during insertion of the injection into the vitreous at the end of phacoemulsification no dislocations of the Aspira-aXA IOL were observed.

\section{DISCUSSION}

In the past, there have been concerns that cataract surgery might not be beneficial to patients 

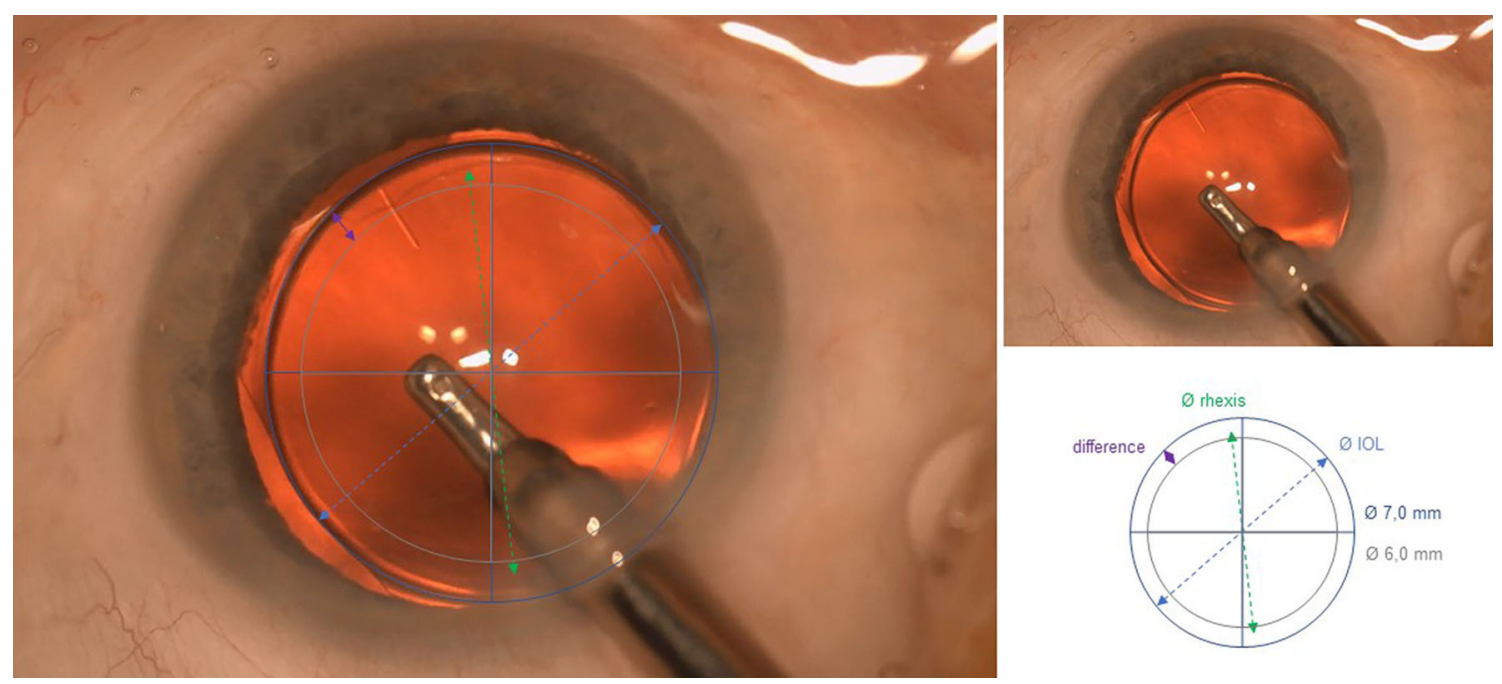

Fig. 4 Intraoperative view with the implanted 7.0-mm IOL, showing the diameters of the rhexis and IOL optic, and differences to the standard-sized IOL

with maculopathy because it may increase the risk of incident $\mathrm{AMD}$ or diabetic retinopathy or the progression of preexisting pathologies $[4,15]$. There is increasing evidence $[5,16]$ that cataract surgery has a positive impact on these patients, resulting not only in an improvement of VA but also improvements in color discrimination and peripheral vision clarity [17]. Our results confirm that VA improvement following cataract surgery is significant, although values are still moderate due to the central scotoma. However, a patient's subjective appraisal is the most important aspect to consider since it is a good indicator of quality of life. Recently, another study showed that the Aspira-aXA IOL with its large optic can enhance patients' quality of life [18]. This study also showed that the Aspira-aXA IOL was comparable in terms of functional performance and small incision size as the standard 6.0-mm IOLs and that it showed good position stability in the capsular bag [18]. In addition, the Aspira-aXA IOL offers the advantages of a 7.0-mm optic in terms of diagnosis and treatment of peripheral retinal pathologies

Measurable "standard parameters," such as VA may not tell the whole story. What matters most to the patient is the restoration of their self-autonomy and that their independence is maintained for a longer time. There is also recent evidence that cataract surgery in AMD patients does not have an impact on the development or progression of the disease [19]. However, a risk-benefit evaluation should be performed for each individual when cataract surgery is considered in this patient population. It is of great importance that the clinician explain the reduced outcomes, so that the patient does not expect a healthy retina and therefore unlimited sight after the surgery.

In our experience, the Aspira-aXA has proven to be a versatile IOL which can be implanted during cataract surgery combined with vitrectomy and combined with intravitreal injection, but it could also be useful in other procedures. Its large optic offers a wide view on the fundus, which is quite helpful in the presence of retinal diseases or for closer follow-ups of the retina [8]. The peripheral areas of the retina can be seen more easily and thus additional surgery in the posterior segment of the eye is also easier. In daily practice this might not be of very much interest to the surgeon focused on the anterior segment. Nonetheless, while performing diagnostic follow-ups or fundus imaging in eyes with additional pathologies, we 
have found the new lens to be advantageous. The large optic size enables the diameter of the capsulorhexis $(6.5 \mathrm{~mm})$ to be increased while still maintaining the recommended rhexis-IOL overlap [10]. This can prevent anterior capsular contraction, shrinkage, and phimosis in posttraumatic eyes and eyes with pseudoexfoliation syndrome or uveitis and diabetes. Dysphotopsia can be generated by the edge of the IOL-optic or a small capsulorhexis. Patients suffering from retinal diseases can benefit from this reduced risk of dysphotopsia as their reduced overall performance cannot be further worsened by these factors. Therefore, implanting a larger IOL may contribute to the prevention of dysphotopsia [20]. "Thinking one step ahead," seems to be very important in highly myopic eyes with the risk of retinal tears and detachments. The wide and undisturbed view might contribute to an easier performance of posterior segment laser treatments and might be beneficial for all posterior segment surgeries.

When intravitreal injection is performed at the end of cataract surgery, a slight IOL shift anteriorly toward the anterior chamber can be observed. This phenomenon has been noticed by several surgeons and described during/after intravitreal injection of triamcinolone acetonide [21]. While injecting the anti-VEGF into the vitreous, pressure starts to push towards the anterior chamber, leading to slight movements of the lens that might result in refractive shifts. In this case series, we did not observe such a phenomenon. Therefore, we assume that because of its 7.0-mm optic design, the lens has a large area of contact with the capsular bag and is additionally stabilized by the back side of the iris; both of these factors may result in a good overall capsular stability. Hence, the larger IOL would resist the IOP during injection from pushing towards the anterior chamber. It even seems that the large optic shields the anterior chamber from any injection effects. Further studies should follow to scientifically evaluate this clinical observation.

\section{CONCLUSION}

To summarize, implanting the large optic IOL in patients suffering from retinal diseases or who are likely to develop posterior segment pathologies in the future would suggest foresight and "thinking one step ahead" or planning in advance without having any additional risk or disadvantage. The 7.0-mm optic enables a larger capsulorhexis, which appears to be beneficial for both patients and ophthalmologists. It is also an easy way to improve the posterior segment view, enhancing the quality of diagnostics and surgery and simplifying further therapies. The surgical effort required, the expenditure of time, and risk are the same with the large optic IOL as with standard procedures. This series of cases verified an improvement in patients' overall quality of life and independence. Moreover, in the postoperative course (6 months) of this small case series no single case of decentration and dysphotopsia was observed. The limitation of this case series is that it is very small and, therefore, comparative, multicenter studies with high case numbers need to follow. Further clinical and in vitro investigations should be made to establish the potential benefit of larger optics to prevent dysphotopsia.

\section{ACKNOWLEDGEMENTS}

We would like to thank K. Pilny for support in designing and creating the illustration in Fig. 2.

Funding. No funding or sponsorship was received for this study or publication of this article. The journal's Rapid Service Fee was funded privately without external subsidies by the main author (Andreas F. Borkenstein).

Authorship. All named authors meet the International Committee of Medical Journal Editors (ICMJE) criteria for authorship for this article, take responsibility for the integrity of the work as a whole, and have given their approval for this version to be published. 
Author Contributions. Andreas F. Borkenstein was the leading author, designed the concept of the study, and wrote the draft of the manuscript. Eva-Maria Borkenstein critically reviewed the manuscript and contributed significantly to the final manuscript.

Disclosures. Andreas F. Borkenstein, EvaMaria Borkenstein have no proprietary or commercial interest in the medical devices that are involved in this manuscript and confirm that they have nothing to disclose.

Compliance with Ethics Guidelines. The current study adhered to the tenets of the Declaration of Helsinki of 1964 and its later amendments, and all patients gave their written informed consent to publish their case. In this case report only standard procedures and devices with CE-mark were used.

Data Availability. The data used to support the findings of this study are available from the corresponding author upon request.

Open Access. This article is licensed under a Creative Commons Attribution-NonCommercial 4.0 International License, which permits any non-commercial use, sharing, adaptation, distribution and reproduction in any medium or format, as long as you give appropriate credit to the original author(s) and the source, provide a link to the Creative Commons licence, and indicate if changes were made. The images or other third party material in this article are included in the article's Creative Commons licence, unless indicated otherwise in a credit line to the material. If material is not included in the article's Creative Commons licence and your intended use is not permitted by statutory regulation or exceeds the permitted use, you will need to obtain permission directly from the copyright holder. To view a copy of this licence, visit http://creativecommons.org/licenses/by$\mathrm{nc} / 4.0 /$.

\section{REFERENCES}

1. Flaxman SR, Bourne RRA, Resnikoff S, et al. Global causes of blindness and distance vision impairment 1990-2020: a systematic review and meta-analysis. Lancet Glob Health. 2017;5(12):e1221-34.

2. Falavarjani KG, Nguyen QD. Adverse events and complications associated with intravitreal injection of anti-VEGF agents: a review of literature. Eye (Lond). 2013;27(7):787-94.

3. Shin HJ, Kim SN, Chung H, Kim TE, Kim HC. Intravitreal anti-vascular endothelial growth factor therapy and retinal nerve fiber layer loss in eyes with age-related macular degeneration: a metaanalysis. Invest Ophthalmol Vis Sci. 2016;57(4): 1798-806.

4. Shuttleworth GN, Luhishi EA, Harrad RA. Do patients with age related maculopathy and cataract benefit from cataract surgery? Br J Ophthalmol. 1998;82(6):611.

5. Kessel L, Erngaard D, Flesner P, Andresen J, Tendal B, Hjortdal J. Cataract surgery and age-related macular degeneration. An evidence-based update. Acta Ophthalmol. 2015;93(7):593-600.

6. Lamoureux EL, Hooper CY, Lim L, et al. Impact of cataract surgery on quality of life in patients with early age-related macular degeneration. Optom Vis Sci. 2007;84(8):683-8.

7. Kessel L, Andresen J, Erngaard D, Flesner P, Tendal $\mathrm{B}$, Hjortdal J. Indication for cataract surgery. Do we have evidence of who will benefit from surgery? A systematic review and meta-analysis. Acta Ophthalmol. 2016;94(1):10-20. https://doi.org/10. 1111 /aos. 12758 .

8. Eter N, Holz FG. Kataraktoperation bei altersabhängiger Makuladegeneration [Cataract surgery in cases of age-related macular degeneration]. Klin Monbl Augenheilkd. 2005;222(5):409-12. https:// doi.org/10.1055/s-2005-858079.

9. Jin-Poi T, Shatriah I, Khairy-Shamel ST, Zunaina E. Rapid anterior capsular contraction after phacoemulsification surgery in a patient with retinitis pigmentosa. Clin Ophthalmol. 2013;7:839-42.

10. Borkenstein AF, Borkenstein EM. Creating hybrid monovision with $7.0 \mathrm{~mm}$ XL optic and high-add AMD intraocular lenses (XL-MAGS) in a patient with retinitis pigmentosa. Case Rep Ophthalmol. 2019;10(3):304-11.

11. Joo CK, Shin JA, Kim JH. Capsular opening contraction after continuous curvilinear capsulorhexis 
and intraocular lens implantation. J Cataract Refract Surg. 1996;22(5):585-90.

12. Takamura Y, Tomomatsu T, Yokota S, Matsumura $\mathrm{T}$, Takihara Y, Inatani M. Large capsulorhexis with implantation of a $7.0 \mathrm{~mm}$ optic intraocular lens during cataract surgery in patients with diabetes mellitus. J Cataract Refract Surg. 2014;40(11): 1850-6.

13. Watanabe A, Shibata T, Ozaki M, Okano K, Kozaki $\mathrm{K}$, Tsuneoka H. Change in anterior chamber depth following combined pars plana vitrectomy, phacoemulsification, and intraocular lens implantation using different types of intraocular lenses. Jpn J Ophthalmol. 2010;54(5):383-6.

14. Chung ST. Reading in the presence of macular disease: a mini-review. Ophthalmic Physiol Opt. 2020;40(2):171-86.

15. Freeman EE, Munoz B, West SK, Tielsch JM, Schein $\mathrm{OD}$. Is there an association between cataract surgery and age-related macular degeneration? Data from three population-based studies. Am J Ophthalmol. 2003;135(6):849-56.

16. Sül S, Karalezli A, Karabulut M. First-year outcomes of cataract surgery combined with intravitreal ranibizumab injection in wet age-related macular degeneration. Turk J Ophthalmol. 2019;49(1):15-9.

17. Tomi A, Moldoveanu A, Marin I. Therapeutic approach in patients with age-related macular degeneration and cataract. Oftalmologia. 2011;55(2):54-9 (in Romanian).

18. Schrecker J, Seitz B, Langenbucher A. Performance einer neuen 7-mm-Intraokularlinse mit Nachbeobachtung über 1,5 Jahre [Performance of a new 7-mm intraocular lens with follow-up over 1.5 years]. Ophthalmologe. 2021. https://doi.org/10. 1007/s00347-021-01504-3.

19. Ehmann DS, Ho AC. Cataract surgery and age-related macular degeneration. Curr Opin Ophthalmol. 2017;28(1):58-62.

20. Bournas P, Drazinos S, Kanellas D, Arvanitis M, Vaikoussis E. Dysphotopsia after cataract surgery: comparison of four different intraocular lenses. Ophthalmologica. 2007;221(6):378-83.

21. Degenring RF, Sauder G. Vitreous prolapse and IOL dislocation during intravitreal injection of triamcinolone acetonide. Graefes Arch Clin Exp Ophthalmol. 2006;244(8):1043-4. 